\title{
Teachers' Knowledge and Understanding of the Malaysian School-Based Oral English Assessment
}

\author{
GURNAM KAUR SIDHU \\ CHAN YUEN FOOK ${ }^{1}$ \\ Faculty of Education \\ Universiti Teknologi Mara \\ yuenfook@hotmail.com ${ }^{1}$ \\ AZLEENA MOHAMAD \\ SMK Dato' Harun \\ Tanjung Karang, Selangor
}

\begin{abstract}
Purpose-The paper sought to investigate TESL teachers' knowledge and understanding of the Malaysian School Based Oral English Assessment (SBOEA) after five years into its implementation in upper secondary ESL classrooms in Malaysian public schools
\end{abstract}

Method - The descriptive study involved a total of 80 TESL trained teachers from the 19 schools located in a district in Selangor, Malaysia. The study employed a three-prong strategy to collect data which included a questionnaire, semi structured interviews and document analysis.

Findings - The findings of the study indicated that there was a low compliance $(58.7 \%)$ rate among teachers to the procedures laid out in the SBOEA Manual with regards to the implementation of SBOEA. The teachers also acknowledged their lack of knowledge and understanding of the SBOEA and a half of the teachers in the study admitted having problems with the scoring criteria. Some teachers highlighted that they felt the SBOEA lacked reliability and validity within and outside the schools.

Significance - The paper explores the possible implications of the study to the enhancement of the implementation of the School Based Oral English Assessment in Malaysian public schools. 
Keywords: School based assessment, oral English test, school based oral English assessment

\section{INTRODUCTION}

Assessment is often seen as an integral part of the teaching and learning equation as it helps both teachers and parents alike to monitor the progress and performance of a student. Researchers such as Dietel, Herman and Knuth (1991) and Borich and Tombari (2004) posit the view that for real learning to take place, effective assessment and evaluation mechanisms have to be put in place and therefore it is pertinent for all stakeholders involved in the business of education to possess sound knowledge and understanding of current assessment and evaluation mechanisms. Traditionally, assessments were summative and centralized and this often resulted in teachers placing a lot of emphasis on examinations. Recent findings (Cunningham, 1998; Dietel, Herman \& Knuth, 1991; Borich \& Tombari, 2004) have however, argued that the one standardized test meted out in summative evaluations is not an accurate indicator of a student's actual performance or ability. Today, assessment policies all around the globe have undergone a gradual but significant paradigm shift from summative to more formative based assessments. Boud and Falchikov (2005) make - the salient point that formative assessment is assessment at regular - intervals of a student's progress with accompanying feedback in order to help to improve the student's performance.

In keeping with global trends of testing and evaluation, both policymakers and educators in Malaysia too are now looking towards school based assessment (SBA) as a catalyst for educational reform. It is seen as a form of leverage for instructional improvement to assist teachers to find out what students are learning in the classroom and how well they are learning it. Such an opinion was first articulated by the then Malaysian Minister of Education, Tan Sri Musa Mohamed when he said that:

\footnotetext{
"we need a fresh and new philosophy in our approach to exams ... . we want to make the education system less exam-oriented and (we) are looking at increasing school based assessment as it would be a better gauge of students' abilities."
}

(New Straits Times: 2003, May 8, p.7). 
In line with the changing trends in assessment, school-based assessment or commonly referred to as PKBS (Penilaian Kendalian Berasaskan Sekolah) in Malaysia was introduced into Malaysian schools under the New Integrated Curriculum for Secondary Schools (KBSM). Since the late 1990s it has adopted 'coursework' for a few subjects in secondary schools such as History, Geography, Living Skills and Islamic Education for the lower secondary classes and Biology, Chemistry and Physics for the upper secondary classes. Later in 2002 the School Based Oral Assessment (SBOA) was implemented for both Bahasa Malaysia (the national language) and English Language for Secondary Five students sitting for the 2003 SPM Examination (equivalent to the UK GCE 'O' Levels Examination). It was against this background that the School Based Oral English Assessment (SBOEA - hereafter) was first implemented in 2002. More importantly it was viewed as a step forward towards formative on-going assessment for enhancing student learning, specifically students' speaking/communicative skills. The implementation of the SBOEA was outlined in a comprehensive document called the SBOEA Manual or Pengendalian Ujian Lisan Berasaskan Sekolah (ULBS) which was published and dsitributed to schools in 2002.

The rationale of the SBOEA as spelt out in the manual highlighted that the SBOEA is an authentic form of assessment that could assess the student's actual speaking activity. It also promotes the teaching and learning process in the ESL classroom as it focuses on ongoing oral assessment from Secondary Four to Secondary Five. Furthermore it is in line with the requirements of the Curriculum Specifications enabling more than one type of oral skill to be assessed. More importantly, the classroom teacher will be the assessor. In such a situation the classroom teacher is the person most familiar with the student and is therefore better informed of the student's actual abilities (Ministry of Education, 2002).

Under the SBOEA, the oral assessment is integrated in the everyday teaching and learning process. Students are assessed a total of three times by their classroom ESL teacher over the two years based on four models of oral assessment. In Secondary Four students are required to do Model 1 (individual presentation) and Model 2 (individual presentation with prompts) whilst in Secondary Five they have a choice between Model 3 (pair work) or Model 4 (group work). The students are graded based on 5 constructs and 6 scoring bands (Excellent $=6$, Good $=4-5$, Satisfactory $=3$, Weak=2, Very Weak=1) with a maximum score of 30 marks ( 6 bands x 5 constructs). 
It is often said that 'change' is the only constant in the workplace. Rae (2006) notes that innovation is inevitable and it is only a matter of time before classroom teachers would have to adopt and accept the way forward. Therefore with the SBOEA making its way into the Malaysian ESL classrooms, the rate of adoption and reaction by teachers may vary considerable. According to Rogers (2003) in his theory of diffusion, there are five categories of product adopters. While some teachers like the 'innovators' may embrace this change willingly with ease, the 'early adopters' and the 'early majority' who may take this new form of assessment when more information is available and they can see and experience the benefits. Others like the sceptical 'late majority' may take more time to bring change into their classrooms. Meanwhile the 'laggards' may resist or stall the change process as they often find change difficult. This group often finds it difficult to move away from their established and traditional 'comfort zones'. Hence it is important to embark on a study to investigate the effectiveness of SBOEA and investigate at what point of adoption these teachers are, so that follow up steps can be taken to ensure the success of new endeavours like the SBOEA.

To measure the effectiveness of a new formative assessment programme like the SBOEA, it is pertinent to examine how teachers view SBOEA and how it is implemented in the ESL classroom. Therefore, this study sought to investigate TESL teachers' perspectives on the implementation of the SBOEA. More specifically

- the study looked into teachers' knowledge and understanding of the implementation of SBOEA at the upper secondary levels; i.e. Secondary Four and Secondary Five levels.

\section{Assessing Speaking}

In most Malaysian ESL classrooms, the assessment of speaking is often a neglected activity with teachers putting more emphasis on reading and writing skills because they are often the skills tested in public examinations. This has also been noted by Chaudhary (2008) who highlights that the teaching and testing of reading and writing skills are more established than speaking in the ESL/EFL classes because of the absence of an accepted list of items to be taught and tested and logistics issues such as time and venues for testing. Furthermore, written examinations can be administered to hundreds of candidates at the same time, while speaking tests have to be administered to examinees individually or in small 
groups, making the whole process expensive and time consuming. Chaudhary (2008, p.3) reiterates that as candidates' responses are oral, hundreds of candidates speaking can reduce the ESL/EFL classroom into "cacophony of unassessable noise".

One of the key challenges in testing speaking is to design tasks that elicit spoken language of the type and quantity that will allow meaningful inferences to be drawn from scores to the candidate's ability on the construct the test is designed to measure (Fulcher, 2003). When assessing speaking, Hartley and Sporing (1999) stress that language assessors are usually interested in the candidate's ability to perform in a range of situations much wider than those that could be sampled during the test. In order to do this, Messick (1989) brought to light two threats the test must avoid to its construct validity. The two threats are construct under-representation and construct-irrelevant variance. Construct under-representation refers to the extent to which a test fails to capture important aspects of the construct the test is intended to measure, while constructirrelevant variance is the extent to which test scores are influenced by factors that are irrelevant to the construct that the test is intended to measure. The SBOEA has to some extent been able to address this shortcoming because formative classroom assessment is continuous and on-going with speaking tasks integrated in everyday ESL lessons.

Luoma (2004) emphasizes that assessing speaking requires teachers to first define the kind of speaking they want to test before proceeding to develop test tasks and rating criteria. Furthermore, Fulcher (2003) notes that the fundamental questions that one need to ask when preparing speaking tasks are: "will the task elicit a performance that can be scored? and "will it be possible to make inferences from the score to the construct we intend to measure?" Furthermore, Weir (1993) reiterates that speaking tasks chosen should also be the most efficient way of obtaining the information about the test-takers. On the subject of test tasks and rating criteria, Luoma (2004) draws attention to the fact that when preparing scoring criteria thought should also be given to the aspect of inter-rater reliability as teachers need to understand the difference between subjective or objective judgment in various purposes of the speaking tests. Arguably, steps must also be taken to ensure credible procedures are established in the test design and rating score whether the final assessment score calls for different raters or just one teacher. Luoma (2004) contends that this consideration is 
often neglected in the ESL/EFL classroom assessment procedures as teachers depend heavily on textbooks and materials that sometimes do not match the speaking tests meted out to the students

Bachman (1990), Weir (1993) and Louma (2004) highlight that for ESL teachers to conduct effective oral assessments, they need to possess cogent knowledge about applied linguistic theories and valid testing procedures so that they can map out the direction of their assessment strategy. Kim (2003) also maintains that assessment needs to be theory-driven as concepts such as validity, reliability and efficiency affect assessment. Bachman (1990) further reiterates that a valid and reliable test is useless if it is not practical. Practicality involves the questions of economy, ease of administration, scoring and interpretation of results. Weir (1993) posits the view that classroom tests should not require expensive specialized equipment or highly trained examiners or raters. He adds that though classroom teachers are often pressured to ensure speaking tests are short and practical since they do not have the liberty of time in assessing students' communicative ability, this should never be allowed to affect test validity.

Adding to this discourse, Fulcher (2003) further draws attention to the fact that assessing speaking involves more than just looking at the type of speaking test and task and other theory driven concepts like validity, reliability, practicability and authenticity. $\mathrm{He}$ notes that there are often a variety of other factors that teachers need to consider such as the learner variables. There is consensus among researchers such as Derwing and Rossiter (2003) and Dalton anf Seidlhofer, (1994) that learner factors such as motivation, attitude, aptitude, L1 background, social status, interests and talent all have been well researched and have proven to contribute to the success or failure in the learner performance in speaking tests and in the acquisition of effective speaking skills. For instance, Fulcher and Reiter (2003) investigated on task difficulty in speaking tests and found that extreme conditions of social powers or imposition may provide an indication of greater task difficulty for some test-takers. Moere (2006), on the other hand, looked at the validity evidence in a university group oral test. His study showed that the test scores were reliable and the greatest systematic variation in test scores is contributed by the person-by-occasion interaction. The study also revealed that candidates' performances or how raters perceive a candidate's ability could be affected by the characteristics of interlocutors and interaction dynamics within the group. 
Breeze (2004) observes that the testing of speaking is still a relative 'new field' within the contexts of applied linguistics and there still remains to date a number of issues that require empirical evidence. Therefore it was against this background of scant empirical research on assessing speaking that this study sought to investigate a schoolbased formative speaking test which has been recently introduced into the Malaysian ESL classroom- commonly referred to as the School Based Oral English Assessment (SBOEA).

\title{
The Study
}

The study employed a descriptive study design to identify the perception of teachers towards the implementation of School Based Oral English Assessment (SBOEA) in Malaysian secondary schools. A descriptive study was chosen to allow a qualitative and quantitative description of the relevant features of the data collected (Cohen, Manion \& Morrison, 2003). More specifically the study sought to investigate teachers' knowledge and understanding of the implementation of the SBOEA with regards to the following:

\author{
objectives of the SBOEA, \\ the implementation of the SBOEA \\ pre administration of the SBOEA \\ administration of the SBOEA \\ post administration of the SBOEA \\ challenges teachers faced \\ suggestions for the enhancement of SBOEA
}

\section{Population Sample}

The study involved all the 19 (18 public and 1 private) secondary schools located in a district in the state of Selangor, Malaysia. The sample comprised all 89 TESL trained teachers teaching English at the upper secondary levels, i.e., Secondary Four and Secondary Five. The total population was included as educational researchers (Cohen, Manion \& Morrison, 2003; Parmjit, Chan \& Sidhu, 2006) stress that for a small population of 100 or less, it is best to survey the entire population. 


\section{Instrumentation}

The research methodology employed a three-pronged approach which involved the use of a questionnaire, semi structured interviews and document analysis. Since it involved a total of 19 schools, a total of nineteen reports from the 19 Chief Assessors were analyzed for the document analyses. For the interviews, two teachers were randomly selected from each of the four (4) types of schools in district - i.e. fully residential school, daily residential school, religious school and day-time daily school. The interview sessions, which involved eight teachers, asked a variety of questions on the implementation of the SBOEA in their respective schools (refer to the Appendix). The SBOEA Chief Assessors Reports were based on the sample provided by the Ministry of Education. These reports looked into a number of the components with a focus on the compliance of schools to the guidelines outlined in the SBOEA Manual. The findings helped to triangulate findings obtained form both the questionnaire and the interviews.

The questionnaire used was adapted from a similar study conducted of Chan, Sidhu \& Mohd. Rizal (2006). The questionnaire consisted of both close and open-ended questions that were used to obtain data both in quantitative and qualitative forms. The adapted questionnaire was validated by two experienced university lecturers to ensure the construct validity of the instrument. A pilot test was carried out in a secondary school in Selangor and the reliability measure for the instrument reported a Cronbach Alpha of 0.80. Quantitative data was analysed by using frequency and percentage. For certain key areas, mean was calculated based on the percent indicated. Besides that, the qualitative data was analysed both inductively and deductively to identify the main themes that emerged based on the research questions posed in this study.

The questionnaire used in this study consisted of 4 parts. Part 1 sought information on the demographic profile of the respondents and included aspects such as gender, age, ethnicity, teacher training qualification, academic qualification, current position and working experience. Apart from that, this part of the questionnaire also elicited information relating to SBOEA which included the exposure to school based assessment, courses on SBOEA and details about its organizer (if any). Part 2 of the questionnaire focused on obtaining information on the respondents' knowledge and understanding of the SBOEA. Part 3 focused on the three following aspects in the SBOEA Manual: the preparation for SBOEA, administering SBOEA and scoring. Finally, Part 4 investigated the implementation 
and feedback aspects of SBOEA. This part of the questionnaire included both open and close ended questions. Most of the other sections required respondents to provide their responses to given items/statements based on a 4-point Likert scale where a score of 1 indicated strong agreement whilst a score of 4 indicated strong disagreement.

\section{FINDINGS}

The following section puts forward the main findings obtained from the survey instrument. Where necessary data from the interview sessions and the Assessors' reports will be added to further triangulate the findings presented in this paper. The survey achieved a 89.9 per cent response rate as 80 out of the total population of 89 Secondary Four and Five TESL teachers responded to the study. Discussion of the findings begins with the respondents' demographic profile, knowledge and understanding of SBOEA, challenges in implementing SBOEA and ways of enhancing the implementation of the assessment.

\section{Respondents' Demographic Profile}

Out of the total 80 teachers, $60 \%$ were females and another $40 \%$ were males. Approximately $18.8 \%$ of the respondents were Diploma holders while the majority of them $(69.9 \%)$ were degree holders and $11.3 \%$ possessed a Masters. Even though close to $90 \%$ of the respondents indicated that they had no official training for the SBOEA, all claimed they were qualified SBOEA assessors as they had been appointed by their school principals. Under the SBOEA, an assessor must posses a letter of appointment to be able to become an assessor. Therefore, most schools often provide a letter of appointment to TESL teachers if they are teaching Secondary Four and Secondary Five ESL classrooms. With no formal training they would without doubt have issues relating to the implementation of and scoring for the SBOEA.

\section{Knowledge and Understanding of School-Based Oral English Assessment}

One of the main aspects investigated in this study was the respondents' basic knowledge and understanding of the implementation of 
SBOEA as spelled out in the SBOEA Manual. We explored teachers' knowledge and understanding on various SBOEA aspects such as the assessment objectives, implementation, preparation, administration and scoring. For effective implementation of SBOEA it is important to ensure $100 \%$ compliance, i.e., adhered to by all teachers. The findings exhibited in Table 1 however revealed that the teachers possessed rather limited knowledge and understanding as most of the scores registered were below the $80 \%$ compliance rate as postulated by the Ministry of Education (MOE) during their training sessions.

Table 1

Teachers' Knowledge and Understanding of the SBOEA

\begin{tabular}{|c|c|c|c|c|}
\hline Area & $\begin{array}{l}\text { Item } \\
\text { No. }\end{array}$ & Item & $\begin{array}{l}\text { Score / } \\
\text { Percent of } \\
\text { Correct } \\
\text { Answer }\end{array}$ & Mean \\
\hline$\sum_{\substack{0 \\
0 \\
0 \\
0}}^{0}$ & 1 & $\begin{array}{l}\text { SBOEA develops a candidate's } \\
\text { ability in line with the learning } \\
\text { objectives as stated in the English } \\
\text { Language Syllabus for Malaysian } \\
\text { Secondary Schools. }\end{array}$ & $\begin{array}{l}56 / 80 \\
70.0 \%\end{array}$ & \multirow{3}{*}{$63.3 \%$} \\
\hline है & 2 & $\begin{array}{l}\text { SBOEA aims to assess candidates' } \\
\text { ability to use English in everyday } \\
\text { life. }\end{array}$ & $\begin{array}{l}62 / 80 \\
77.5 \%\end{array}$ & \\
\hline & 3 & $\begin{array}{l}\text { SBOEA has eight testing } \\
\text { objectives. }\end{array}$ & $\begin{array}{l}34 / 80 \\
42.5 \%\end{array}$ & \\
\hline & 4 & $\begin{array}{l}\text { SBOEA offers four models of oral } \\
\text { assessment. }\end{array}$ & $\begin{array}{l}36 / 80 \\
45.0 \%\end{array}$ & \multirow[b]{2}{*}{$45.0 \%$} \\
\hline 是: & 5 & $\begin{array}{l}\text { Candidates are assessed twice } \\
\text { in Secondary Four and once in } \\
\text { Secondary Five. }\end{array}$ & $\begin{array}{l}36 / 80 \\
45.0 \%\end{array}$ & \\
\hline 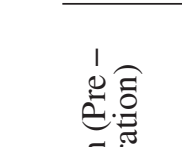 & 6 & $\begin{array}{l}\text { Candidates are allowed to choose } \\
\text { their own activities from the list of } \\
\text { activities provided in the SBOEA } \\
\text { manual. }\end{array}$ & $\begin{array}{l}64 / 80 \\
80.0 \%\end{array}$ & \multirow{3}{*}{$65.8 \%$} \\
\hline . & 7 & $\begin{array}{l}\text { Candidates decide on the topic and } \\
\text { task for the assessment. }\end{array}$ & $\begin{array}{l}48 / 80 \\
60.0 \%\end{array}$ & \\
\hline 2 & 8 & $\begin{array}{l}\text { Candidates prepare their task with } \\
\text { teacher's consultation. }\end{array}$ & $\begin{array}{l}46 / 80 \\
57.5 \%\end{array}$ & \\
\hline
\end{tabular}




\begin{tabular}{|c|c|c|c|c|}
\hline Area & $\begin{array}{l}\text { Item } \\
\text { No. }\end{array}$ & Item & $\begin{array}{c}\text { Score / } \\
\text { Percent of } \\
\text { Correct } \\
\text { Answer }\end{array}$ & Mean \\
\hline \multirow{4}{*}{ 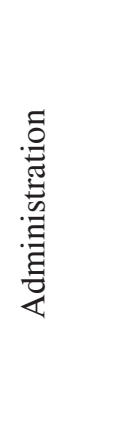 } & 9 & $\begin{array}{l}\text { SBOEA is conducted during the } \\
\text { teaching and learning process. }\end{array}$ & $\begin{array}{l}52 / 80 \\
65.0 \%\end{array}$ & \multirow{4}{*}{$57.5 \%$} \\
\hline & 10 & $\begin{array}{l}\text { Candidates are allowed to make } \\
\text { reference to the text during } \\
\text { assessment. }\end{array}$ & $\begin{array}{l}38 / 80 \\
47.5 \%\end{array}$ & \\
\hline & 11 & $\begin{array}{l}\text { Each candidate is given a time limit } \\
\text { to speak. }\end{array}$ & $\begin{array}{l}52 / 80 \\
65.0 \%\end{array}$ & \\
\hline & 12 & $\begin{array}{l}\text { Each candidate is allowed to do } \\
\text { the assessment of each model more } \\
\text { than once. }\end{array}$ & $\begin{array}{l}42 / 80 \\
52.5 \%\end{array}$ & \\
\hline \multirow{8}{*}{ 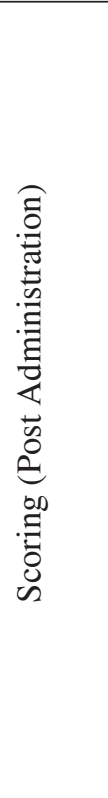 } & 13 & $\begin{array}{l}\text { Candidates are assessed based on } \\
\text { five constructs. }\end{array}$ & $\begin{array}{l}50 / 80 \\
62.5 \%\end{array}$ & \multirow{8}{*}{$62.1 \%$} \\
\hline & 14 & $\begin{array}{l}\text { Marks are awarded in five bands: } \\
\text { Excellent, Good, Satisfactory, } \\
\text { Weak and Very Weak. }\end{array}$ & $\begin{array}{l}64 / 80 \\
80.0 \%\end{array}$ & \\
\hline & 15 & $\begin{array}{l}\text { Each band is provided a list of cri- } \\
\text { teria/ descriptor. }\end{array}$ & $\begin{array}{l}58 / 80 \\
72.5 \%\end{array}$ & \\
\hline & 16 & $\begin{array}{l}\text { The highest score for each band is } \\
6 \text {. }\end{array}$ & $\begin{array}{l}48 / 80 \\
60.0 \%\end{array}$ & \\
\hline & 17 & $\begin{array}{l}\text { The grand total for SBOEA is } 30 \\
\text { marks. }\end{array}$ & $\begin{array}{r}58 / 80 \\
72.5 \%\end{array}$ & \\
\hline & 18 & $\begin{array}{l}\text { The highest score is recorded as the } \\
\text { final score. }\end{array}$ & $\begin{array}{l}40 / 80 \\
50.0 \%\end{array}$ & \\
\hline & 19 & $\begin{array}{l}\text { Scores are recorded in the Oral } \\
\text { English Test (O.E.T) Individual } \\
\text { Profile form. }\end{array}$ & $\begin{array}{l}80 / 80 \\
100.0 \%\end{array}$ & \\
\hline & 20 & $\begin{array}{l}\text { Candidates sign the form after each } \\
\text { assessment. }\end{array}$ & $\begin{array}{l}34 / 80 \\
42.5 \%\end{array}$ & \\
\hline & & Overall Mean & & $58.7 \%$ \\
\hline
\end{tabular}

Note: The mean was obtained from the average score achieved by teacher respondents on each item

\section{Objectives of SBOEA}

The SBOEA Manual has identified eight testing objectives: converse on a topic effectively, speak fluently, speak coherently, give appropriate responses, speak using the language appropriately 
within context, speak using correct and acceptable pronunciation, speak using correct grammar and speak using a wide range of appropriate vocabulary (MOE, 2002). The findings showed that even though a majority of the respondents were aware of the general and specific objectives of the SBOEA, only less than half (45\%) were aware of its main testing objectives. This is rather disappointing as these objectives are of paramount importance since the testing objectives include the assessment constructs which every SBOEA Assessor must be aware of. Teachers must be aware of the objectives to ensure they help students to achieve the learning outcomes postulated by the SBOEA.

\section{Implementation of SBOEA}

For this section, respondents were asked about the models of SBOEA and the frequency of oral assessment conducted in their classroom. With regards to the implementation, respondents indicated limited knowledge of the SBOEA as only $45 \%$ of the respondents were aware that there were four models of oral assessment, and that candidates were assessed twice in Secondary Four and once in Secondary Five. This could probably be due to the fact that not all the respondents may be teaching at both the upper secondary levels. = In the administration of SBOEA, the results were divided - into three phases: 'pre-administration', 'while administration' and 'post administration'. The pre-administration phase involved the preparations respondents made prior to the actual administration of SBOEA. The manual states that candidates of SBOEA need to consult with their teacher in deciding on the type of activity, choice of topic and task for the intended assessment. In this oral assessment, teachers fulfilled the role of assessor, consultant, prompter and facilitator.

Respondents had better knowledge and understanding on the preparation of the SBOEA as a majority (80\%) of them indicated awareness that candidates were allowed to choose their own activities and can decide on the topic and task for the assessment. However, only slightly more than half of the respondents $(57.5 \%)$ knew that school candidates need to prepare their task with teacher's consultation.

The 'administration' phase highlighted the procedures involved while conducting the oral assessment. Under the stipulated 
regulations the assessment is to be conducted during the teaching and learning process; however only $65 \%$ of teacher respondents were aware of this. Furthermore, slightly more than half (52.5\%) were aware of the fact that candidates were allowed to do the assessment of each model more than once, and less than half $(47.5 \%)$ realized that candidates were actually allowed to make reference to the text during assessment. Besides that, only $65 \%$ of them knew that there was no time duration for student presentation as stipulated in the SBOEA Manual. Findings at this phase implied that teacher respondents were not completely aware of the procedures involved in conducting the oral assessment thus, may not conform to the intended practice.

According to the SBOEA Manual, the post administration phase highlighted the scoring procedures of SBOEA. The scoring criteria had changed three times in two years, moving from eight constructs to five constructs. Some of the respondents were rather confused about the scoring criteria. Therefore a lack of effective compliance was also seen in the post administration especially in the scoring $(62.1 \%)$ of the SBOEA. The findings further exhibited that only $62.5 \%$ of the respondents were aware that the SBOEA was at present assessed based on five and not eight constructs. This was a matter of concern as these teachers were already in the process of assessing students' speaking skills. A majority (80\%) of the respondents indicated an awareness of the five performance bands used in the scoring scheme, but only $75 \%$ acknowledged that descriptors were provided for each band. Furthermore only $60 \%$ were conscious of the fact that the maximum score was 6 , as the previous scoring system used a maximum score of 10 . Slightly more teacher respondents were aware that the grand total for the SBOEA was now 30 marks. It was also a matter of grave concern that only $50 \%$ of the respondents were aware that the highest score is to be recorded as the students' final score, raising the question of whether teachers were indeed recording accurately students' scores for the SBOEA. However, respondents revealed 100\% compliance to the recording to the scores and all of them knew that scores are to be recorded in the Oral English Test (O.E.T) Individual Profile form. Nevertheless less than half $(42.5 \%)$ were conscious of the fact that students must sign the form after each assessment. This showed that some of the respondents did not adhere to the given guidelines as there is a column provided for the candidate's signature in the assessment form. 


\section{Challenges in Implementing SBOEA}

This study also investigated the major challenges faced by teachers implementing SBOEA in their ESL classroom. Based on data obtained from the open ended questions posed in the survey instrument (Part 4. Item 4), the interview sessions and the 19 Assessors' reports, the findings (Table 2) can be summarized into three main categories namely, the teacher factor, the student factor and the educational system.

\section{Table 2}

Challenges Identified by TESL Teachers

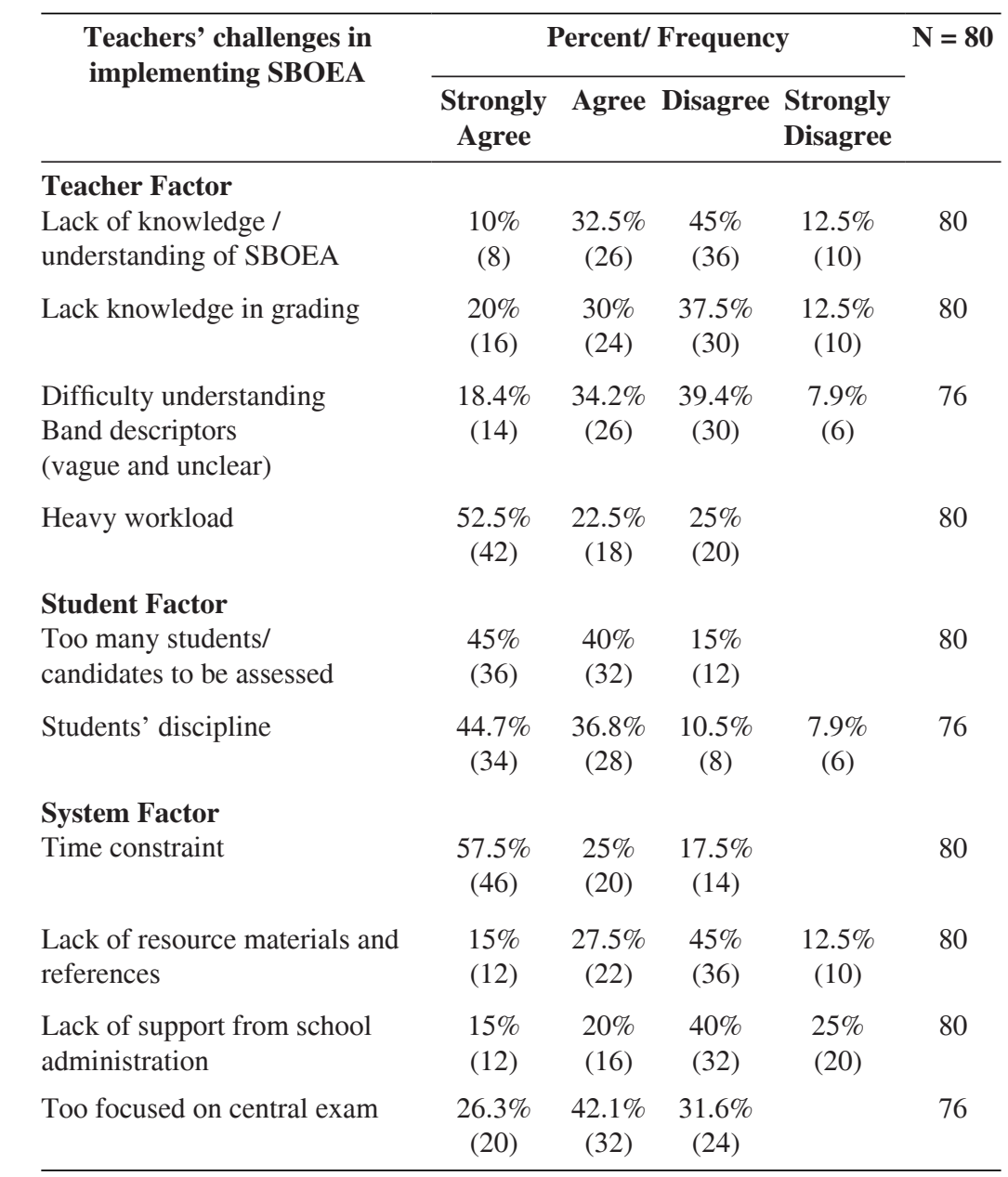


The findings presented in Table 2 highlight that teachers face seven (7) major challenges in conducting the SBOEA. The challenges are as follows: lack of knowledge/understanding of SBOEA, lack of knowledge in giving scores, heavy workload, too many students/ candidates to be assessed, students' discipline, time constraint, and schools been too exam-oriented.

The results indicated that close to $42.5 \%$ of the respondents claimed lack of knowledge and/or understanding of the assessment as a challenge. This implies that knowledge may impede teachers' ability to conduct the SBOEA effectively in the ESL classrooms. Furthermore, the findings also revealed that $50 \%$ of the respondents agreed that they lacked knowledge in grading and another $52.6 \%$ felt they had some difficulty understanding the band descriptors as they were unclear.

The band descriptors were also identified as one of the challenges from the interview. An informant claimed that it was difficult for him to differentiate between 'excellent' and 'good'. He added that this was because he made comparison with the students in his school. Thus, he said what he claimed to be excellent, may pass as satisfactory in another school. This claim was similar to one made by another interview informant. She claimed that she tended to compare her students with the weakest class. Hence, at times, she marked her students high when she saw them doing better than the weaker ones. This showed that teacher respondents did not understand the descriptors, thus affecting the scoring of SBOEA. When the guideline was vague, it was difficult for the assessors to interpret and award scores to their candidates.

A total of 60 respondents identified heavy workload as a challenge to assess student's communicative ability. 42 teacher respondents strongly agreed that this was a challenge to them while 18 stated that they agreed. This showed that workload was an obstacle for the respondents in their effort to implement the assessment in their ESL classroom. Heavy workload was ranked the second highest among the challenges identified. The number of candidates to be assessed was also seen as a challenge: $45 \%$ of the respondents strongly agreed that it was difficult to assess a large number of students. It was seen as one of the major challenges as the percentage was high on 'strongly agree' option compared to 'agree' option. This challenge was closely related to the large classroom size in their schools. An interview informant commented that she had three (3) classes of Secondary Four with an average of 45 students 
in each class. She complained that it was tiring and unpractical to assess about 135 candidates twice in a school year. Hence, having a large number of students did influence the implementation of SBOEA in the classroom.

Student discipline was also seen as one of the major challenges to SBOEA. 34 respondents strongly agreed that it was one of the constraints they faced in implementing SBOEA, while 28 opted for 'agree'. This claim was supported by the responses obtained in the heads of assessor report. Analysis revealed that more than half of them identified students' seriousness and preparation as a constraint in conducting SBOEA. Evidence from interview informants also showed that students were not serious about SBOEA, thus delayed the task of assessing them. It can be concluded that the problem of oral assessment was not only time consuming but also stressful for the teacher.

Time was also seen as a challenge in implementing SBOEA. This was evident as 66 respondents identified this as one of the major challenges. A total of $57.5 \%$ of respondents selected the 'strongly agree' option, indicating that this was a major constraint to them. This claim was supported by the data gathered from the document analysis, which revealed that 13 out of 19 heads of school assessors identified time as a constraint in their report. One interview informant she stressed that assessing 135 students was time consuming. At the same time, she did not have time to do it in class that she had to do it in isolation. This showed that time constraint has led the teacher to violate the requirement of conducting the assessment during the teaching and learning process.

$68.4 \%$ of the respondents also felt that school was too exam-oriented, and this posed a challenge to SBOEA. During the interview session these teachers highlighted that students, parents and schools (especially top school management) paid more attention to centralized public examinations compared to school based assessments. The results of the public examinations were taken seriously by both schools and parents as a measure of school accountability and individual pride (Lim \& Zhao, 2005). This has led to a change in the teaching practice in schools - teaching to the test, thus setting a rather depressing exam-oriented culture among students, teachers, parents and administrators alike (Yunus, 2001). Teachers tended to focus on the content of the subject syllabus forecasted for the examination, abandoning other aspects of the syllabus that may be useful for a holistic development. 


\section{Enhancing the implementation of SBOEA}

The study also sought respondents' views on to how SBOEA could be further enhanced. The findings are displayed in Table 3. Data was gathered from the survey (Part 4, Item 5) administered during the study and the interview responses. $70 \%$ of the respondents in this study highlighted that teachers should be provided with samples of students' performance for each band. This suggestion was probably seen as a solution to the current bands descriptors which were perceived 'vague and unclear'. It also indicated that respondents were concerned with the scoring of SBOEA. Teachers pointed out in the interview sessions that if sample scripts were presented for each band, the reliability of scoring within classes and schools could be further established.

Table 3

Enhancement of the SBOEA $(n=80)$

\section{Suggestions}

Provide samples for each band descriptors

Reduce the number of assessments

Specify teacher's role in the consultation process

Send assessors for SBOEA courses

Provide a variety of activities

Specify SBOEA's time frame
Frequency Percentage

$(\%)$

70.0

50

48

60.0

36

45.0

22

52 of the respondents $(65 \%)$ suggested that the number of assessments be reduced. Currently there are two assessments for Form Four and one for Form Five. Interview data indicated that teachers felt that the SBOEA involved "too much paper work"; large class enrolments did not help. A majority saw reducing the number of assignments as the 'best solution' as they had to deal with having a large number of candidates to assess. They also believed that it could provide them with more time to conduct the assessment.

The findings also revealed that respondents would like the teacher's role in the consultation process to be further clarified. This was because they did not want the candidates to depend too much 
on the teachers for assistance. Findings from interview sessions further highlighted that there was concern about how much help teachers should give if the final score went towards the public SPM examination. There was concern that some schools gave ready made scripts to their students to memorize whilst others offered little or no help.

Respondents also suggested the need for more training and exposure to SBOEA. $60 \%$ of the respondents felt that they needed to attend courses on the SBOEA. The demographic profile indicated that $90 \%$ of the respondents had not attended any course on SBOEA. Thus, this could have been the reason for the recommendation, although it ranked fourth place in the list.

Since the SBOEA has to be conducted during the English language lessons, teachers were concerned about implementation. Close to $45 \%$ of the respondents saw the need to provide teachers with samples of a variety of activities that could be done in the ESL classroom. Currently the manual has no such examples.

- Interview sessions also revealed that teachers were concerned about when SBOEA must be conducted. $28 \%$ said that they would appreciate a specific time frame so that all schools would conduct the SBOEA during the same period. This would enhance the coordination of school, regional or district meetings.

Besides the above enhancement strategies, a number of teachers also pointed out that the ministry had to be more effective in - disseminating information. Some respondents felt that information was slow to reach the rural schools. There were instances when they realized that they were doing the wrong thing as information did not reach them in time. Some respondents recommended that the Malaysian Examination Syndicate should opt for a more technology-savvy idea such as having an e-portal for the SBOEA. A few teachers also drew attention to the type of training model used. They felt that the current Cascade Training Model used by the Ministry of Education was ineffective. They suggested that more in-house and centralized training workshops be held to increase teachers' knowledge and understanding of the SBOEA.

\section{IMPLICATIONS AND RECOMMENDATIONS}

This study involved only 80 TESL teachers from 19 secondary schools in a district located in the state of Selangor. Due to the small sample size, the findings cannot be generalized to the total 
population of secondary TESL teachers in Malaysia. Nevertheless a number of pertinent issues and concerns can be drawn from the study with regards to the implementation of the SBOEA, which would benefit upper secondary Malaysian teachers in general.

It is perhaps important to note that effective implementation of any programme demands a $100 \%$ compliance rate to stipulated guidelines. This study however has indicated that teachers' knowledge and understanding of the implementation of the SBOEA at the 19 schools left much to be desired. All aspects of the SBOEA implementation - i.e. Purpose, Implementation Pre Administration, During Administration, Post Administration were well below the mastery level of $80 \%$. The lack of compliance probably reflects a lack of effective training and monitoring procedures. School management and education personnel at district, state or national education departments perhaps need to be more aware of this and take appropriate action.

Another important concern is teacher competency. Teachers admitted to a lack of knowledge and understanding of the SBOEA implementation and further expressed their concerns about grading students. Teachers' failure to comply with SBOEA guidelines and their lack of understanding and knowledge clearly is a cause for concern. The relevant authorities need to address this issue as close to $90 \%$ of the respondents in this study have had no formal training and exposure to SBOEA. More effective training modules and e-learning portals could be seen as alternatives to the traditional cascade training models currently implemented.

Furthermore frequent changes in scoring criteria coupled with vague descriptors and bands suggest a lack of thought the SBOEA by the relevant authorities. This has left many teachers confused. Furthermore only about three quarters of the teachers were knowledgeable about the band descriptors. Such a scenario may reduce the reliability of the SBOEA. There is no denying that the reliability of speaking tests also rests upon the competency of oral examiners or raters. Fulcher (2003) notes that in most speaking assessments inter-rater reliability tends to be low, and therefore more time should be devoted to examiner training and standardization. Opting for a training manual that would provide SBOEA assessors a more hands-on-training workshop would ensure theory-based concepts of testing such as validity and reliability are established (Louma, 2004; Fulcher, 2003; Weir, 1993). 
Students' commitment, proficiency and discipline are also issues that the TESL teacher needs to come to terms with. A majority of students still need help as speaking has been a much neglected skill in the Malaysian ESL classroom. Hence, mechanisms need to be put in place to help students. Arguably, teachers, with their heavy workloads need to be advised as to the amount of help and the form of supervision that they need to provide. These aspects need to be addressed in the SBOEA Manual. Teacher workload and constraints of having to assess many students within a stipulated time frame are also bones of contention for the TESL teachers. It is perhaps timely for Malaysian ESL classrooms to opt for more current approaches to assessment such as those provided in computer-assisted language learning (CALL). Researchers such as Pennington (1999), Neri, Cucchiarini, Strik and Boves (2002), highlight that CALL has provided the assessment of speaking skills newer perspectives and directions in the development of tests and actual scoring of performance.

\section{Concluding Thoughts}

The TESL teacher in the Malaysian secondary classroom should understand that formative assessments like the SBOEA are the way forward, as they are to be a permanent feature in the Malaysian school system. On 16 October 2010, the Malaysian Education Minister announced that the centralized public examination for the lower secondary students (known as PMR) would be abolished and replaced by School Based Assessments (SBA). He also stressed that more measures would be taken to enhance school based assessments (Tan, 2010). This was further reiterated by the Education deputy director, Datuk Noor Rezan Bapoo Hashim who highlighted that SBA would be of 'acceptable standards' ensuring that 'teachers and school heads are accountable for matters pertaining to school assessment'. She also added that these would include 'the quality of questions', the marking scheme and ensuring assessments are carried out fairly "without favouring or victimizing individual students" (Tan, 2010, p. E3). These comments also imply that issues similar to those highlighted in this study concerning adherence to guidelines, maintaining standards and accountability should be addressed by teachers implementing school based assessments in their classrooms. 
At this juncture, it is perhaps pertinent to point out that formative types of assessment, if properly implemented in schools would be a powerful means of improving students' learning as it provides ongoing feedback to the students (Black \& William, 1998 as cited in Lo Yiu Chun, 2006). Consequently, Malaysian teachers should embrace the SBOEA. While it is still at its infancy and despite its initial drawbacks, they should view it positively and work collaboratively to overcome these limitations. Teachers must understand that formative assessment endeavours such as the SBOEA have much more to offer than one test score provided by traditional centralized examinations. More importantly, the SBOEA is a step in the right direction to enhance speaking skills, which have been neglected thus far in Malaysian ESL classrooms.

\section{REFERENCES}

Bachman, L.F. (1990). Fundamental considerations in language testing. Oxford: Oxford University Press.

Borich, G.D., \& Tombari, M.L. (2004). Educational assessment for the elementary and middle school classroom. New Jersey: Pearson, Merill Prentice Hall.

Boud, D. and Falchikov, N. (2005). Redesigning assessment for learning beyond higher education, In Brew, A. and Asmar, C. (Eds.), Research and development in higher education 28. Sydney: HERDSA, 34-41.

Breeze, R. (2004). Book Review: Testing Second Language Speaking by Glenn Fulcher. In TESL-EJ Journal. Vol. 8 No. 1 Retrieved October 2, 2009, from http://www-writing.berkeley.edu.

Chan, Y.F., Sidhu, G.K., \& Md. Rizal Md. Yunus. (2006). The knowledge and best practices of secondary school ESL Teachers in school-based assessment. Shah Alam: IRDC, UiTM.

Chaudhary, S. (2008). Testing spoken English for credit within the Indian university system. TESL-EJ, December 2008, 12 (3), $1-8$.

Cohen, L., Manion, L., \& Morrison, K. (2003). Research methods in education. New York: Routledge/Falmer.

Cunningham, G.K. (1998). Assessment in the classroom: Constructing and interpreting tests. London: The Falmer Press. 
Dalton, C., \& Seidlhofer, S. (1994). Pronunciation. New York: Oxford University Press.

Derwing, T.M., \& Rossiter, M.J. (2003). The effects of pronunciation instruction on the accuracy, fluency, and complexity of L2 accented Speech. Applied Language Learning, 13, 1-18.

Dietel, R.J., Herman, J.L., \& Knuth, R. A. (1991). What does research say about assessment? Oak Brook: North Central Regional Educational Laboratory. Retrieved from http://www. ncrel./org.

Fulcher. G. (2003). Testing second language speaking. Harlow: Pearson Longman.

Fulcher, G. \& R. M. Reiter. (2003). Task difficulty in speaking tests. Language Testing. 20 (3), $321-344$.

Hartley, L. \& M. Sporing. (1999). Teaching communicatively: Assessing communicatively? Language Learning Journal, $19,73-79$.

Lim, C. S., \& Zhao, X. P. (2005). Assessment and examination system: A comparative study between Malaysia and Shanghai (China). Paper presented at the The Third East Asia Regional Conference on Mathematics Education. Retrieved from http:// math.ecnu.edu.cn.

Lo Yiu Chun (2006). Practice and challenges of school-based formative assessment. Hong Kong: The Hong Kong Institute of Education.

- Luoma, S. (2004). Assessing speaking. New York: Cambridge University Press.

Messick, S. (1989). Validity. In Linn, R. L. (Ed) Educational measurement. New York: Macmillan/ American Council on Education.

Ministry of Education, Malaysia. (2002). Pengendalian Ujian Lisan Berasaskan Sekolah (ULBS). Malaysia: KPM.

Moere, A. V. (2006). Validity evidence in a university group oral test. Language Testing, 23 (4), $411-440$.

Neri, A., Cucchiarini, C., Strik, H., \& Boves, L. (2002). The pedagogytechnology interface in computer assisted pronunciation training. Computer Assisted Language Learning, 15(5), 441467.

New Straits Times. (2003, May 8). Malaysian education system to be less exam oriented. New Straits Times, p.7.

Parmjit, S., Y. F. Chan \& G. K. Sidhu. (2006). A comprehensive guide to writing a research proposal. Selangor: Venton Publication. 
Pennington, M.C. (1999). Computer-aided pronunciation pedagogy: Promise, limitations, directions. Computer Assisted Language Learning, 12(5), 427-440.

Rae, J. (2006), Bringing innovation to the classroom. Insight. Retrieved from http://www.businessweek.com

Rogers, E. M. (2003). Diffusion of innovations (5th ed.). New York: Free Press.

Tan, E.L. (2010, October 17). School tests will be fair. The Star Education supplement, p. E3.

Weir, C. J. (1993). Communicative language testing. London: Prentice - Hall.

\section{APPENDIX: SEMI STRUCTURED INTERVIEWS}

Warm - up questions:

1. How long have you been teaching in this school?

2. How long have you been teaching English?

3. Are you an assessor for School Based Oral English Assessment (SBOEA)?

4. How long have you been an assessor for SBOEA?

Implementation:

5. Is SBOEA fully implemented in your school?

6. In your opinion, is it easy to carry out SBOEA in your classroom?

Reliability:

7. Do you think SBOEA shows your students' true ability in using the language?

Challenges:

8. Do you face any problems when you carry out SBOEA in your classroom?

9. What are the problems you face?

Suggestions to further enhance SBOEA:

10. What suggestions do you have to further enhance the implementation of SBOEA? 


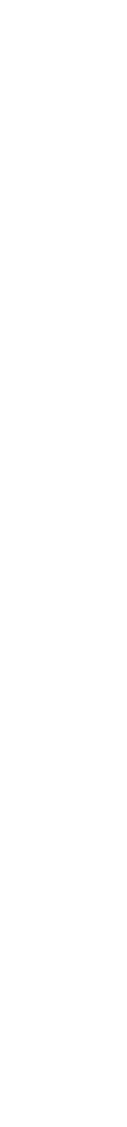

